\title{
Racial variation in umbilical cord blood sex steroid hormones and the insulin-like growth factor axis in African-American and white female neonates
}

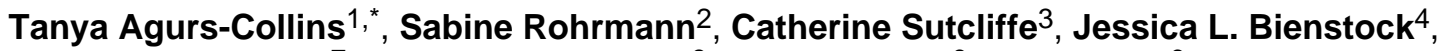 \\ Deborah Monsegue ${ }^{7}$, Folasade Akereyeni ${ }^{8}$, Gary Bradwin ${ }^{9}$, Nader Rifai ${ }^{9}$, Michael N. \\ Pollak $^{10}$, and Elizabeth A. Platz ${ }^{3,5,6,{ }^{*}}$
}

${ }^{1}$ Division of Cancer Control and Population Sciences, National Cancer Institute, Bethesda, Maryland ${ }^{2}$ Department of Cancer Epidemiology and Prevention, Institute of Social and Preventive Medicine, University of Zurich, Zurich, Switzerland ${ }^{3}$ Department of Epidemiology, Johns Hopkins Bloomberg School of Public Health, Baltimore, Maryland ${ }^{4}$ Department of Gynecology and Obstetrics, Johns Hopkins University School of Medicine, Baltimore, Maryland ${ }^{5}$ Sidney Kimmel Comprehensive Cancer Center, Hopkins Medical Institutions, Baltimore, Maryland ${ }^{6} J a m e s$ Buchanan Brady Urological Institute, Johns Hopkins Medical Institutions, Baltimore, Maryland ${ }^{7}$ Howard University Cancer Center, Howard University, Washington, District of Columbia ${ }^{8}$ Howard University Human Genome Center, Howard University, Washington, District of Columbia ${ }^{9}$ Department of Laboratory Medicine, Harvard Medical School and Children's Hospital, Boston, Massachusetts ${ }^{10}$ Department of Medicine and Oncology, Jewish General Hospital and McGill University, Montreal, Quebec, Canada

\section{Abstract}

\begin{abstract}
Purpose-To evaluate whether there is racial variation in venous umbilical cord blood concentrations of sex steroid hormones and the insulin-like growth factor (IGF)-axis between female African-American and white neonates.

Methods-Maternal and birth characteristics and venous umbilical cord blood samples were collected from 77 African-American and 41 white full-term uncomplicated births at two urban hospitals in 2004 and 2005. Cord blood was measured for testosterone, dehydroespiandrosteronesulfate (DHEAS), estradiol, sex-steroid hormone binding globulin (SHBG) by immunoassay. IGF-1, IGF-2, and IGF binding protein-3 (IGFBP-3) were measured by ELISA. Crude and multivariable-adjusted geometric mean concentrations were computed for the hormones.
\end{abstract}

Results-African-American neonates weighed less at birth (3,228 vs. 3,424 grams, $p<0.004)$ than whites. Birth weight was positively correlated with IGF-1, IGFBP-3 and the molar ratio of IGF1 to IGFBP-3, but inversely correlated with the molar ratio of IGF-2 to IGFBP-3. Adjusted models showed higher testosterone $(1.82 \mathrm{vs} .1 .47 \mathrm{ng} / \mathrm{mL}, \mathrm{p}=0.006)$ and the molar ratio of testosterone to SHBG ( 0.42 vs. $0.30, \mathrm{p}=0.03)$ in African-American compared to white female

\footnotetext{
*Drs. Agurs-Collins (formerly of Howard University Cancer Center) and Platz (Hopkins) co-proposed and co-conducted this study. A companion paper on racial variation in the in utero milieu for male births in the context of prostate cancer has been published [Rohrmann S, Sutcliffe CG, Bienstock JL, Monsegue D, Akereyeni F, Bradwin G, Rifai N, Pollak MN, Agurs-Collins T, Platz EA. Racial variation in sex steroid hormones and the insulin-like growth factor axis in umbilical cord blood of male neonates. Cancer Epidemiol Biomarkers Prev. 2009 May; 18 (5):1484-91. PubMed PMID: 19423525; PubMed Central PMCID: PMC3012385]. This decision was made a priori to allow the investigators at the two institutions involved in this U54 to each take the lead on one of the papers.

Requests for reprints: Dr. Tanya Agurs-Collins, Division of Cancer Control and Population Sciences, National Cancer Institute, Bethesda, MD; Tel: (301) 594-6637, Fax: 301-480-2087; collinsta@mail.nih.gov.
} 
neonates. IGF-1, IGF-2, and IGFBP-3 were lower in African-American compared to white female neonates, but only the difference for IGF-2 remained significant (496.5 vs. $539.2 \mathrm{ng} / \mathrm{mL}, \mathrm{p}=0.04)$.

Conclusion-We provide evidence of racial variation in cord blood testosterone and testosterone to SHBG in African-American compared to white female neonates, and higher IGF-2 in white compared to African-American female neonates. Findings suggest plausible explanations for a prenatal influence on subsequent breast cancer risk and mortality. Further work is needed to confirm these observations.

\section{Keywords}

umbilical cord blood; IGF axis; sex steroid hormones; African American

\section{Introduction}

Breast cancer is the leading cause of cancer death among US women. Although the incidence is higher for white women $>40$ years of age, recent US trends reveal a crossover in age-adjusted incidence with higher rates in African-American $<40$ years of age $[1,2]$. Overall, black women are far more likely to be diagnosed with aggressive breast cancer at a later-stage, less likely to receive stage-appropriate treatment, and have lower stage-for-stage survival rates $[3,4]$. A number of biological, socioeconomic and lifestyle factors that are known to be related to increased risk might also be contributing to this differential in prognosis seen in black as compared to white women. Among the endogenous factors associated with breast cancer risk are circulating levels of sex steroid hormones and the insulin-like growth factor (IGF) axis. We hypothesize that perturbations in endogenous hormones and growth factors in utero may also account for a small part of the racial disparity in breast cancer incidence and mortality.

Estrogens and androgens have been established as mitogens in normal breast as well as breast cancer cells, and levels of these hormones have been shown to play a role in determining breast cancer risk $[5,6]$. When examining racial differences, several epidemiologic studies have shown a direct association between elevated levels of estradiol, estrone and low SHBG with breast cancer risk, particularly in African American women compared to whites. A study in 420 pregnant women found African Americans to have higher concentrations in androstenedione, testosterone, and progesterone than Caucasian or Hispanic women [7], which may influence risk of adult cancer in their offspring. Additionally, insulin-like growth factors (IGF)-1 and IGF-2 have been implicated in breast tumorigenesis because of their ability to stimulate mitogenesis and their key role in mammary gland cell proliferation and survival $[8,9]$. Investigations of racial/ethnic differences reveal that African-American women have elevated levels of total IGF-1 and free IGF-1 relative to whites [10-12], with similar trends being observed among both prepubertal and pubertal African-American girls [13] [14].

Over 20 years ago Trichopoulos [15] postulated that exposure to elevated endogenous hormones during pregnancy might contribute to subsequent breast cancer risk in adulthood. During pregnancy, sex steroid hormones are greatly elevated and play an essential role in normal development of the breast in the mother, whereas the IGF-axis stimulates cell division and differentiation and regulates fetal and weight gain $(12,13)$. These hormones and growth factors have been estimated to be at least 10 times higher in pregnant than nonpregnant women, and they steadily increase with advancing gestational age [15]. Although these hormones are needed for normal growth and development, they also play an important role in breast carcinogenesis. Epidemiologic studies suggest that in utero hormonal perturbations can impact perinatal factors, such as birth weight and length. As a result, 
perinatal measures are used as surrogate indicators of intrauterine exposure. Several metaanalyses provide evidence for an association between increased birth weight, birth length, and higher maternal and paternal age with subsequent breast cancer risk in adulthood [1618]. High birth weight appears to be associated specifically with premenopausal breast cancer risk. In the Swedish Twin Registry, for example, birth weight $>3000 \mathrm{~g}$ was associated with increased risk of breast cancer diagnosis at or before 50 years (HR, 1.57; 95\% CI, 1.03-2.42) [19]. Higher birth weights are, in turn, associated with elevated estrogen and IGF-1 concentrations in umbilical cord blood [20-23]. Despite this evidence supporting an association between exposure to sex steroid hormones and IGF-axis hormones in utero and breast cancer risk in adulthood, few studies have explored potential contributions of these factors to the observed racial disparities in breast cancer risk.

We investigated differences in venous umbilical cord blood concentrations of sex steroid hormones and components of the IGF-axis between African-American and white female neonates. This study provides the opportunity to fill the gap in knowledge about racial variations in the hormonal and growth factor in utero environment, taking into account racial differences in maternal and birth characteristics. Further, we considered whether racial variation in these factors may be a plausible explanation for notably higher US breast cancer incidence in premenopausal and higher mortality in both pre-and postmenopausal AfricanAmerican women.

\section{Materials and Methods}

\section{Study population}

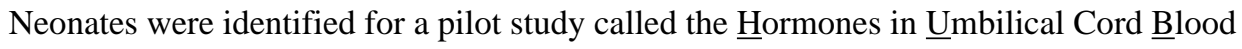
Study (HUB Study), which was a project that was part of the National Cancer Institute partnership awarded to the Howard University Cancer Center and the Sidney Kimmel Comprehensive Cancer Center at Johns Hopkins. The aim of the NCI partnership grant was to enhance the research, training, outreach, and education missions of both institutions. The Institutional Review Board of Prince George's Hospital Center and the Johns Hopkins Bloomberg School of Public Health approved both studies.

The delivery room nurses were asked to anonymously collect demographic data and venous umbilical cord samples for neonates delivered at the Prince George's Hospital Center in Cheverly, MD (Hospital 1) and the Johns Hopkins Hospital in Baltimore, MD (Hospital 2). Inclusion criteria for neonates were full term birth defined as between the $38^{\text {th }}$ and $42^{\text {nd }}$ gestational week, birth weight between 2500 and $4000 \mathrm{~g}$, no major birth defects, and singleton birth. For the mother, the exclusion criteria included pregnancy complications (e.g., pre-eclampsia, toxemia, and hypertension), gestational diabetes, diabetes mellitus, thyroid disease, use of hormonal medications during pregnancy, and known growth hormone deficiency. For the neonates, both the mother and father were required to be of the same race, either African-American or white.

Between February 2004 and June 2005, demographic data and cord blood samples were collected for eligible births at the two hospitals by the delivery room nurses. Using a standardized form, the nurses collected the following information: month and time (quadrant) of day of the birth, birth weight, placental weight, mother/child's race, and mother's age, parity (number of live births), and gravidity (number of pregnancies). A total of $15 \mathrm{~mL}$ of blood from the umbilical cord vein was drawn into two tubes containing sodium EDTA and immediately stored in a refrigerator. Within approximately 12 hours and at room temperature, the samples were centrifuged for 15 minutes at $2400 \mathrm{rpm}$. Plasma, buffy coat, and red cells were aliquoted into cryovials and stored at $-70^{\circ} \mathrm{C}$. 
We collected cord blood specimens from 127 female births at the two hospitals. Of the total sample, 5 were excluded because they did not meet the birth weight eligibility criterion and 4 were excluded because they were not of adequate quality or did not meet other eligibility criteria. Thus, the final sample size was 118, of which 41 were white and 77 AfricanAmerican. Before shipping and testing, all samples were randomly arrayed by hospital and race and blinded quality control cord blood samples were included to assess assay reliability. An overnight courier was used to ship plasma samples on dry ice to the two collaborating laboratories.

\section{Exposure assessment}

Sex steroid hormones, testosterone, estradiol, dehydroespiandrosterone-sulfate (DHEAS) and SHBG were measured by competitive immunoassay (1010 Elecsys autoanalyzer, Roche Diagnostics, Indianapolis, IN) in the laboratory of Nader Rifai, PhD, (Children's Hospital, Boston, MA). IGF-1, IGF-2 and IGFBP-3 were measured by ELISA (Diagnostics Systems Laboratory) in the laboratory of Michael N. Pollak, MD (Jewish General Hospital and McGill University, Montreal, Canada). The laboratory technicians were blinded to race and hospital. The lowest detection limits of the assays were: testosterone $0.02 \mathrm{ng} / \mathrm{mL}$, estradiol 5 $\mathrm{pg} / \mathrm{mL}$, DHEAS, and SHBG $0.35 \mathrm{nmol} / \mathrm{L}$. IGF-1, $0.03 \mathrm{ng} / \mathrm{mL}$; IGF-2, $24 \mathrm{ng} / \mathrm{mL}$; and IGFBP-3, $0.04 \mathrm{ng} / \mathrm{mL}$. The quality control specimens had the following coefficients of variation: testosterone 6.9\%; estradiol 15.7\%, SHBG 8.3\%; DHEAS; IGF-1, 12.3\%; IGF-2, $6.2 \%$; and IGFBP-3, $6.8 \%$.

\section{Statistical analysis}

Several hormones were not normally distributed so we calculated the geometric mean for all plasma concentrations of sex steroid hormones, SHBG, and IGF-axis factors in the cord blood of the African-American and white female neonates. Differences in sex steroid hormones and growth factors were tested by race using the t-test. We also present the geometric means for all sex steroid hormones and growth factors adjusted for birth weight, placental weight, mother's age and parity, and quadrant of day of birth, since the distribution of possible determinants of cord blood hormone levels may differ by race and thereby confound the findings. We estimated differences in geometric means using generalized linear models.

We also examined whether the molar ratio of testosterone and estradiol to SHBG and the molar ratio of IGF-1 and IGF-2 to IGFBP-3 varied by race crudely and after adjusting for the other possible determinants of cord blood concentrations. This analysis was important since binding proteins modify the bioavailability of steroid and peptide hormones. The molar ratios provide an estimate of the free or bioavailable amount of hormone or IGF in circulation. SHBG is the major carrier of both testosterone and estradiol in circulation and when bound to SHBG, these hormones are not available for androgenic and estrogenic signaling. Similarly, IGFBP-3 is the major carrier of IGF-1 and IGF-2 in circulation, and when bound IGF-1 and -2 are not available to signal. We did not measure free levels of these analytes. All analyses were conducted using SAS v. 9 (SAS Institute, Cary, NC).

\section{Results}

Table 1 shows the birth characteristics of 118 mothers and their female babies by race. Mothers of African-American neonates were significantly younger than mothers of white neonates ( 24.1 vs. $28.2 \mathrm{yr}, \mathrm{p}<0.0005)$ and were more likely to have $\geq 3$ live births. Also, African American babies weighed less at birth $(3,228$ vs. 3,424 grams, $p<0.004)$ and had lighter placental weights ( 659 vs. $675 \mathrm{~g}$ ) than white babies, although the latter was not statistically significant. Since African Americans were born at two different hospitals, we 
compared maternal and birth-related characteristics between the two hospitals. African Americans births from hospital 2 compared to hospital 1 had heavier placental weight (691 vs. $613 \mathrm{~g}, \mathrm{p}<0.03$ ) and their mothers were more likely to be nulliparous. The time of day of birth varied within both hospitals. Since the patterns were similar for African-American births at hospitals 1 and 2 when compared to white births, we combined all AfricanAmerican births into one category, which is included in subsequent analyses.

Spearman correlation coefficients were calculated for birth characteristics with cord blood hormone and IGF-axis concentrations taking into account race (Table 2). Birth weight was statistically significantly correlated in a positive direction with concentrations of IGF-1, IGFBP-3 and the molar ratio of IGF1 to IGFBP-3, but inversely correlated with the molar ratio of IGF-2 to IGFBP-3. In addition, we observed a statistically significant inverse correlation between parity and concentrations of testosterone, estradiol, and a near significant association with the molar ratio of estradiol to SHBG. A statistically significant positive correlation was observed between placental weight and IGFBP-3 concentrations.

Median and interquartile ranges for cord blood sex steroid hormone and growth factor concentrations by race are shown in Table 3. There were no major differences in cord blood concentrations between African-American and white neonates with respect to the distributions of sex steroid hormones, SHBG and the molar ratios of testosterone and estradiol to SHBG. However, African Americans had significantly lower median concentrations of IGF-1, IGF-2 and IGFBP3 than whites, although no racial differences were found for the molar ratios of IGF-1 and IGF-2 to IGFBP-3.

Crude and multivariable-adjusted geometric mean hormone and growth factor concentrations and $95 \%$ confidence intervals by race are shown in Table 4 . In our examination of crude geometric means (model A), we did not observe statistically significant differences in cord blood concentrations of testosterone, DHEAS, estradiol and SHBG by race. Although not significant, the cord blood levels were slightly higher among white neonates compared to African Americans, with the exception of testosterone. After adjusting for birth weight, placental weight, mother's age, parity and time of day of birth (model B), the concentration of testosterone was significantly higher in African-American neonates than in whites $(1.79$ vs. $1.49 \mathrm{ng} / \mathrm{mL}, \mathrm{p}=0.02)$. The mutually adjusted model (model C) as opposed to the crude (model A) or the adjusted model (model B) revealed significantly stronger racial differences for testosterone concentration between African Americans and whites ( 1.82 vs. $1.47 \mathrm{ng} / \mathrm{mL}, \mathrm{p}=0.006$ ). The difference between African-American and white female neonates with respect to the crude geometric mean molar ratios of testosterone to SHBG (model A) was near significance $(\mathrm{p}=0.06)$, but after multivariable adjustment (model B), this molar ratio was statistically significantly higher in African-American neonates compared with whites $(0.42$ vs. $0.30, \mathrm{p}=0.03)$.

In contrast to sex steroid hormones, cord blood concentrations of the growth factors differed significantly by race (Table 4). In the crude model (model A), African-American neonates had statistically significantly lower cord blood concentrations for IGF-1, IGF-2, and IGFBP-3 when compared to white neonates. Although not statistically significant, the molar ratio of IGF-1 to IGFBP-3 was lower in African-American than in white neonates ( 0.19 vs. $0.22, \mathrm{p}=0.08$ ). After multivariable adjustment (model $\mathrm{B}$ ), the concentrations were still slightly lower in African Americans, but only the difference for IGF-2 remained significantly lower in African American neonates than in whites (496.5 vs. $539.2 \mathrm{ng} / \mathrm{mL}$, $\mathrm{p}=0.04$ ). In this model, there were no statistically significant racial differences in the molar ratios for IGF-1 and IGF-2 to IGFBP-3. 


\section{Discussion}

The purpose of this study was to evaluate whether there is racial variation in venous umbilical cord blood concentrations of sex steroid hormones and the insulin-like growth factor (IGF)-axis between female African-American and white neonates. Our analyses were adjusted for birth weight, placental weight, mother's age, mother's parity, and time of day of birth. We did not find racial differences in cord blood concentrations of estradiol, DHEAS, SHBG and the molar ratio of estradiol to SHBG. However, we did observe both higher testosterone levels and the molar ratio of testosterone to SHBG, an indicator of bioavailable testosterone, in the cord blood of African-American compared to white female neonates. Cord blood concentrations of IGF-1, IGF-2, and IGFBP-3 were significantly lower in African-American than white female neonates in the crude model, but only IGF-2 remained significant in the multivariable model. In both the crude and multivariate models, the molar ratios for IGF-1 and IGF-2 to IGFBP-3 did not differ by race.

\section{Sex steroid hormones}

Two studies examined racial/ethnic differences in umbilical cord blood sex steroid hormones in female neonates [21,24]. One found higher non significant estradiol levels in Asian than Caucasian and Hispanic neonates [21]. The other study did not find ethnic/racial differences between European, Maori, South Asian, and Pacific Islands [24]. These findings are consistent with studies that combined female and male neonates [22, 25]. After controlling for factors related to pregnancy, Troisi et al. [22] did not find significant differences in cord blood estradiol levels between Chinese and white neonates. Contrary to these findings, Lagiou et al. [26] found significantly higher levels of cord blood estradiol and SHBG in Chinese compared to whites in a combined sample of female and male neonates. Another study found non-significant differences in cord blood estradiol and DHEAS concentrations between African American and white female and male neonates [25]. Similar to that study, we did not find significant differences in cord blood estradiol, DHEAS and SHBG concentrations between African American and white neonates, although the levels tended to be lower in our African-American neonates. It has been suggested that lower SHBG may be inversely correlated with measures of hematopoietic stem cell potential, which may increase risk for breast cancer [27]. Understanding the relationship between low SHBG concentrations and breast cancer risk in our sample needs further investigation. We did not find correlations between birth weight and cord levels of estradiol, DHEAS or SHBG, which is consistent with other studies [25, 28]; however, estradiol was inversely correlated with parity. Only one study found a positive correlation between cord blood DHEAS levels with birth weight in normal, singleton pregnancies [25]. Overall, our lack of an association for racial differences in estradiol, DHEAS and SHBG appears to corroborate the findings in other studies [21, 22, 24, 25].

Few studies found significantly elevated testosterone levels in African American women during the early weeks of gestation when compared to whites [25, 29]. When measuring cord blood testosterone concentrations, studies found higher levels for Chinese compared to white neonates [22, 26]; whereas others did not find significant differences [24, 25]. We found significantly higher testosterone levels in African American compared to white neonates. Elevated intrauterine testosterone concentrations are associated with restricted fetal growth in both animal and human studies [30-32] and is believed to reduce the nutrient supply to the placenta and/or modify placental function, thus restricting growth [30]. In our study, African American female neonates, who had higher cord blood testosterone levels than whites, also had smaller birth weights compared to whites. However, we found no correlation between testosterone with birth weight for both African-American and white neonates. This finding is consistent with other studies [25,33]. Whether racial differences in 
adult premenopausal breast cancer is associated with in utero perturbations to testosterone levels remains to be determined.

\section{IGF-Axis}

Few studies have examined racial variation in umbilical cord blood levels of IGF-1, IGF-2 and IGFBP-3 and the literature is somewhat mixed. Racial differences in IGF-1 cord blood concentrations were seen in US whites compared with Chinese neonates [26, 34]; whereas Chinese neonates had higher levels of IGF-2 compared to white neonates. However, others did not find differences in cord IGF-1 concentrations among other racial/ethnic groups in female neonates [21, 24] and a sample of combined female and male neonates [22]. We observed differences in growth factor concentrations in cord blood between AfricanAmerican and white female neonates. Although not statistically significant, African American neonates had lower concentrations of IGF-1 and lower birth weights than did the white neonates.

The literature suggests that cord blood IGF-1 concentrations are positively correlated with birth weight and length among taller US white women [34]. Specifically, higher cord IGF-1 and IGFBP-3 concentrations have been correlated with higher birth weight, birth length, head circumference and other anthropometry measures [21, 35-37] whereas lower IGF-1 and IGFBP-3 concentrations are associated with preterm or small for gestational age neonates $[37,38]$. The relationship between IGF-1 and birth weight is important since they both have been associated with risk of breast cancer [16-18]. In our study, African American neonates had lower IGF-1 concentrations and lower birth weights, which is contrary to the hypothesis that elevated intrauterine IGF-1 concentrations increases risk for breast cancer later in life.

We found significantly lower cord blood concentrations of IGF-2 in African American neonates compared to whites. Studies suggest that IGF-2 is important for fetal growth and development $[39,40]$ and concentrations are lower in preterm rather than full term neonates $[41,42]$. One study reported higher circulating levels of IGF- 2 with birth weight and length among Chinese compared to white neonates [34]. Others found a weak relationship to birth size/weight [43], and the molar ratio of IGF-2 to soluble IGF-2/mannose-6-phosphate receptor with birth weight [44]. Our finding of lower mean IGF-2 concentrations among African American neonates does not support the hypothesis that elevated levels may mediate the associated of prenatal factors with subsequent breast cancer in this population, but instead suggest a potential risk among white neonates with higher IGF-2 expression. Similar to our results for African American neonates, a low ratio of IGF-2:IGFBP3 was found in Afro-Caribbean women than whites, after adjustment for mean body mass index [10].

We compared our patterns of cord blood hormone and growth factors in females to a separate investigation that examined male neonates using samples from the HUB study [45]. We found that the patterns of the racial difference were similar in female and males. The bioavailable testosterone in cord blood was higher in both female and male AfricanAmericans than in whites and that IGF axis components were lower in both female and male African-Americans than whites.

In our study the African American female neonates were smaller and had lower placental weights when compared to the white neonates, which has been documented in the US population. Fetal growth is regulated by hormones and growth factors as well as the nutritional environment. During fetal development there is programming of several biological systems, which can be negatively impacted by intrauterine growth restriction [46] and influence disease risk later in life. In addition to prenatal or in utero growth restriction, postnatal birth weight might also increase breast cancer risk. For example, small for 
gestational age infants who experience accelerated growth in childhood develop insulin resistance as a result of rapid weight gain [47]. Insulin resistance and/or hyperinsulinemia are considered risk factors not only for diabetes, but also breast cancer [48-50], as hyperinsulinemia can promote breast cancer cell proliferation. Moreover, adults and children who were born small for gestational age experience metabolic abnormalities (e.g. obesity, insulin resistance, hypertension and dyslipidemia) similar to metabolic syndrome. A recent study found that metabolic syndrome was more prevalent in triple-negative breast cancer than non-triple negative patients [51]. Taken together, the intrauterine environment plays a critical role in fetal growth and development, and thus, can set the stage for increased breast cancer risk later in life. Studies are needed to fully elucidate the biological mechanism (s) and/or epigenetic changes that occur in utero as well as the role of catch up growth in low birth weight babies and subsequent breast cancer.

\section{Strengths and Limitations}

There are a number of strengths such as the exclusion of neonates who were very small $(<$ $2500 \mathrm{~g}$ ) or large (> $4000 \mathrm{~g}$ ) and were born to mothers who experienced pregnancy complications such as preeclampsia or gestations diabetes. Also, we included only female neonates because of our interest in risk for adulthood breast cancer. At the time of birth, blood was drawn from the umbilical cord vein, which represents blood flow from the placenta to the baby. Umbilical cord blood is believed to be a good indicator of fetal exposure to hormonal and growth factor systems because it reflects three sources: fetal production, placental production, and maternal production.

We presented crude and adjusted hormone and growth factor concentrations, both of which may provide valuable information on racial differences in cord blood levels. The differing plasma levels represent the actual levels experienced by the fetus at the end of pregnancy. Thus, variation in these actual levels might be an explanation for the racial variation in breast cancer and mortality later in life.

There are several possible limitations to our study. We did not collect information on maternal lifestyle factors such as diet, physical activity and smoking, which may affect circulating concentrations of sex steroid hormones and growth factors in umbilical cord blood. Also, we could not determine if the stress of labor and delivery affected hormone levels for both fetal and maternal blood samples. Additionally, the sex steroid hormone concentrations measured in the HUB study were in the lower range compared to previous studies $[25,26,52]$. Our growth factor concentrations were in the higher range compared to another study [21], but similar to results reported by Lagiou et al. [26]. The differences in the cord blood concentrations among studies might be reflective of differences among the study populations (e.g. racial/ethnicity, BMI), the collection of venous versus arterial cord blood, differences in blood collection procedures or in assay methods and variability.

Another potential limitation is that we collected samples from two different hospitals. Reflecting the demographics of their catchment areas, Hospital 1 included AfricanAmerican births whereas hospital 2 included both African-American and white births. Because the maternal and birth characteristics did not differ markedly between the AfricanAmerican babies born at the two hospitals, we combined data for the African-American births in the final analyses.

\section{Conclusion}

In conclusion, we observed racial differences in cord blood concentrations of sex steroid hormones and the IGF axis between African-African and white female neonates. Significant racial differences were found for circulating levels of testosterone and the molar ratio for 
testosterone to SHBG, after controlling for maternal and birth characteristics. The higher bioavailable testosterone concentrations in African American female neonates compared with whites is consistent with what has been reported in the literature and may mediate the association of prenatal factors with subsequent breast cancer risk. Contrary to elevated testosterone concentrations, African American female neonates exhibited significantly lower concentrations of IGF-2, which is essential for early fetal growth and has been shown to be a marker for tumor growth and survival. Research is needed to identify those factors that influence perturbations in circulating hormones and growth factors (e.g. mother's anthropometric measurements and lifestyle factors) in the intrauterine environment and determine what role, if any, they contribute to breast cancer racial disparities. Understanding these mechanisms can help to advance efforts in breast cancer prevention and control.

\section{Acknowledgments}

We thank Anna DeNooyer, MHS, research assistant, and Stacey Meyerer, laboratory manager, both at the Johns Hopkins Bloomberg School of Public Health, for their assistance in the conduct of this study, the delivery room nurses at the Prince George's Hospital Center and the Johns Hopkins Hospital for collecting the cord blood specimens, and Yuzhen Tao in the laboratory of Dr. Pollak for overseeing the laboratory assays.

Grant support: National Cancer Institute grant U54 (Howard CA091431) and U54 (Hopkins CA091409).

\section{References}

1. Anderson WF, Rosenberg PS, Menashe I, Mitani A, Pfeiffer RM. Age-related crossover in breast cancer incidence rates between black and white ethnic groups. J Natl Cancer Inst. 2008; 100:18041814. [PubMed: 19066264]

2. Brinton LA, Sherman ME, Carreon JD, Anderson WF. Recent trends in breast cancer among younger women in the United States. J Natl Cancer Inst. 2008; 100:1643-1648. [PubMed: 19001605]

3. McBride R, Hershman D, Tsai WY, Jacobson JS, Grann V, Neugut AI. Within-stage racial differences in tumor size and number of positive lymph nodes in women with breast cancer. Cancer. 2007; 110:1201-1208. [PubMed: 17701948]

4. Morris GJ, Mitchell EP. Higher incidence of aggressive breast cancers in African-American women: a review. J Natl Med Assoc. 2008; 100:698-702. [PubMed: 18595572]

5. Baglietto L, Severi G, English DR, et al. Circulating steroid hormone levels and risk of breast cancer for postmenopausal women. Cancer Epidemiol Biomarkers Prev. 2010; 19:492-502. [PubMed: 20086116]

6. Eliassen AH, Missmer SA, Tworoger SS, et al. Endogenous steroid hormone concentrations and risk of breast cancer among premenopausal women. J Natl Cancer Inst. 2006; 98:1406-1415. [PubMed: 17018787]

7. Potischman N, Troisi R, Thadhani R, et al. Pregnancy hormone concentrations across ethnic groups: implications for later cancer risk. Cancer Epidemiol Biomarkers Prev. 2005; 14:1514-1520. [PubMed: 15941965]

8. Pacher M, Seewald MJ, Mikula M, et al. Impact of constitutive IGF1/IGF2 stimulation on the transcriptional program of human breast cancer cells. Carcinogenesis. 2007; 28:49-59. [PubMed: 16774935]

9. Yu H, Shu XO, Li BD, et al. Joint effect of insulin-like growth factors and sex steroids on breast cancer risk. Cancer Epidemiol Biomarkers Prev. 2003; 12:1067-1073. [PubMed: 14578144]

10. McCormack VA, Dowsett M, Folkerd E, et al. Sex steroids, growth factors and mammographic density: a cross-sectional study of UK postmenopausal Caucasian and Afro-Caribbean women. Breast Cancer Res. 2009; 11:R38. [PubMed: 19545414]

11. Pinheiro SP, Holmes MD, Pollak MN, Barbieri RL, Hankinson SE. Racial differences in premenopausal endogenous hormones. Cancer Epidemiol Biomarkers Prev. 2005; 14:2147-2153. [PubMed: 16172224] 
12. Setiawan VW, Cheng I, Stram DO, et al. Igf-I genetic variation and breast cancer: the multiethnic cohort. Cancer Epidemiol Biomarkers Prev. 2006; 15:172-174. [PubMed: 16434607]

13. Casazza K, Higgins PB, Fernandez JR, Goran MI, Gower BA. Longitudinal analysis of the insulinlike growth factor system in African-American and European American children and adolescents. J Clin Endocrinol Metab. 2008; 93:4917-4923. [PubMed: 18782874]

14. Girgis R, Abrams SA, Castracane VD, Gunn SK, Ellis KJ, Copeland KC. Ethnic differences in androgens, IGF-I and body fat in healthy prepubertal girls. J Pediatr Endocrinol Metab. 2000; 13:497-503. [PubMed: 10803867]

15. Trichopoulos D. Hypothesis: does breast cancer originate in utero? Lancet. 1990; 335:939-940. [PubMed: 1970028]

16. Park SK, Kang D, McGlynn KA, et al. Intrauterine environments and breast cancer risk: metaanalysis and systematic review. Breast Cancer Res. 2008; 10:R8. [PubMed: 18205956]

17. Xu X, Dailey AB, Peoples-Sheps M, Talbott EO, Li N, Roth J. Birth weight as a risk factor for breast cancer: a meta-analysis of 18 epidemiological studies. J Womens Health (Larchmt). 2009; 18:1169-1178. [PubMed: 19630536]

18. Xue F, Michels KB. Intrauterine factors and risk of breast cancer: a systematic review and metaanalysis of current evidence. Lancet Oncol. 2007; 8:1088-1100. [PubMed: 18054879]

19. Oberg S, Cnattingius S, Sandin S, Lichtenstein P, Iliadou A. Birth weight-breast cancer revisited: is the association confounded by familial factors? Cancer Epidemiol Biomarkers Prev. 2009; 18:2447-2452. [PubMed: 19690178]

20. Mucci LA, Lagiou P, Tamimi RM, Hsieh CC, Adami HO, Trichopoulos D. Pregnancy estriol, estradiol, progesterone and prolactin in relation to birth weight and other birth size variables (United States). Cancer Causes Control. 2003; 14:311-318. [PubMed: 12846361]

21. Shibata A, Harris DT, Billings PR. Concentrations of estrogens and IGFs in umbilical cord blood plasma: a comparison among Caucasian, Hispanic, and Asian-American females. J Clin Endocrinol Metab. 2002; 87:810-815. [PubMed: 11836326]

22. Troisi R, Lagiou P, Trichopoulos D, et al. Cord serum estrogens, androgens, insulin-like growth factor-I, and insulin-like growth factor binding protein-3 in Chinese and U.S. Caucasian neonates. Cancer Epidemiol Biomarkers Prev. 2008; 17:224-231. [PubMed: 18199728]

23. Vatten LJ, Odegard RA, Nilsen ST, Salvesen KA, Austgulen R. Relationship of insulin-like growth factor-I and insulin-like growth factor binding proteins in umbilical cord plasma to preeclampsia and infant birth weight. Obstet Gynecol. 2002; 99:85-90. [PubMed: 11777516]

24. Simmons D. Interrelation between umbilical cord serum sex hormones, sex hormone-binding globulin, insulin-like growth factor I, and insulin in neonates from normal pregnancies and pregnancies complicated by diabetes. J Clin Endocrinol Metab. 1995; 80:2217-2221. [PubMed: 7608282]

25. Troisi R, Potischman N, Roberts J, et al. Associations of maternal and umbilical cord hormone concentrations with maternal, gestational and neonatal factors (United States). Cancer Causes Control. 2003; 14:347-355. [PubMed: 12846366]

26. Lagiou P, Samoli E, Okulicz W, et al. Maternal and cord blood hormone levels in the United States and China and the intrauterine origin of breast cancer. Ann Oncol. 2011; 22:1102-1108. [PubMed: 20943596]

27. Savarese TM, Strohsnitter WC, Low HP, et al. Correlation of umbilical cord blood hormones and growth factors with stem cell potential: implications for the prenatal origin of breast cancer hypothesis. Breast Cancer Res. 2007; 9:R29. [PubMed: 17501995]

28. Nagata C, Iwasa S, Shiraki M, Shimizu H. Estrogen and alpha-fetoprotein levels in maternal and umbilical cord blood samples in relation to birth weight. Cancer Epidemiol Biomarkers Prev. 2006; 15:1469-1472. [PubMed: 16896034]

29. Henderson BE, Bernstein L, Ross RK, Depue RH, Judd HL. The early in utero oestrogen and testosterone environment of blacks and whites: potential effects on male offspring. Br J Cancer. 1988; 57:216-218. [PubMed: 3358915]

30. Carlsen SM, Jacobsen G, Romundstad P. Maternal testosterone levels during pregnancy are associated with offspring size at birth. Eur J Endocrinol. 2006; 155:365-370. [PubMed: 16868152] 
31. Manikkam M, Crespi EJ, Doop DD, et al. Fetal programming: prenatal testosterone excess leads to fetal growth retardation and postnatal catch-up growth in sheep. Endocrinology. 2004; 145:790798. [PubMed: 14576190]

32. Whitehouse AJ, Maybery MT, Hart R, et al. Free testosterone levels in umbilical-cord blood predict infant head circumference in females. Dev Med Child Neurol. 2010; 52:e73-e77. [PubMed: 20002113]

33. Simmons D, France JT, Keelan JA, Song L, Knox BS. Sex differences in umbilical cord serum levels of inhibin, testosterone, oestradiol, dehydroepiandrosterone sulphate, and sex hormonebinding globulin in human term neonates. Biol Neonate. 1994; 65:287-294. [PubMed: 8054396]

34. Lagiou P, Hsieh CC, Lipworth L, et al. Insulin-like growth factor levels in cord blood, birth weight and breast cancer risk. Br J Cancer. 2009; 100:1794-1798. [PubMed: 19417744]

35. Chiesa C, Osborn JF, Haass C, et al. Ghrelin, leptin, IGF-1, IGFBP-3, and insulin concentrations at birth: is there a relationship with fetal growth and neonatal anthropometry? Clin Chem. 2008; 54:550-558. [PubMed: 18202160]

36. Hung TY, Lin CC, Hwang YS, Lin SJ, Chou YY, Tsai WH. Relationship between umbilical cord blood insulin-like growth factors and anthropometry in term newborns. Acta Paediatr Taiwan. 2008; 49:19-23. [PubMed: 18581724]

37. Orbak Z, Darcan S, Coker M, Goksen D. Maternal and fetal serum insulin-like growth factor-I (IGF-I) IGF binding protein-3 (IGFBP-3), leptin levels and early postnatal growth in infants born asymmetrically small for gestational age. J Pediatr Endocrinol Metab. 2001; 14:1119-1127. [PubMed: 11592569]

38. Martos-Moreno GA, Barrios V, Saenz de PM, et al. Influence of prematurity and growth restriction on the adipokine profile, IGF1, and ghrelin levels in cord blood: relationship with glucose metabolism. Eur J Endocrinol. 2009; 161:381-389. [PubMed: 19561044]

39. Gohlke BC, Fahnenstich H, Dame C, Albers N. Longitudinal data for intrauterine levels of fetal IGF-I and IGF-II. Horm Res. 2004; 61:200-204. [PubMed: 14764950]

40. Zhao P, Zhang XL, Yu C, Lu XY, Wang YM. [Umbilical cord serum levels of insulin-like growth factor-1, insulin and growth hormone in neonates with intrauterine growth retardation]. Zhongguo Dang Dai Er Ke Za Zhi. 2010; 12:771-773. [PubMed: 20959038]

41. Barrios V, Argente J, Pozo J, et al. Insulin-like growth factor I, insulin-like growth factor binding proteins, and growth hormone binding protein in Spanish premature and full-term newborns. Horm Res. 1996; 46:130-137. [PubMed: 8894668]

42. Lo HC, Tsao LY, Hsu WY, Chen HN, Yu WK, Chi CY. Relation of cord serum levels of growth hormone, insulin-like growth factors, insulin-like growth factor binding proteins, leptin, and interleukin- 6 with birth weight, birth length, and head circumference in term and preterm neonates. Nutrition. 2002; 18:604-608. [PubMed: 12093439]

43. Fant M, Salafia C, Baxter RC, et al. Circulating levels of IGFs and IGF binding proteins in human cord serum: relationships to intrauterine growth. Regul Pept. 1993; 48:29-39. [PubMed: 7505470]

44. Ong K, Kratzsch J, Kiess W, Costello M, Scott C, Dunger D. Size at birth and cord blood levels of insulin, insulin-like growth factor I (IGF-I), IGF-II, IGF-binding protein-1 (IGFBP-1), IGFBP-3, and the soluble IGF-II/mannose-6-phosphate receptor in term human infants. The ALSPAC Study Team. Avon Longitudinal Study of Pregnancy and Childhood. J Clin Endocrinol Metab. 2000; 85:4266-4269. [PubMed: 11095465]

45. Rohrmann S, Sutcliffe CG, Bienstock JL, et al. Racial variation in sex steroid hormones and the insulin-like growth factor axis in umbilical cord blood of male neonates. Cancer Epidemiol Biomarkers Prev. 2009; 18:1484-1491. [PubMed: 19423525]

46. Barker DJ. In utero programming of chronic disease. Clin Sci (Lond). 1998; 95:115-128. [PubMed: 9680492]

47. Jaquet D, Gaboriau A, Czernichow P, Levy-Marchal C. Insulin resistance early in adulthood in subjects born with intrauterine growth retardation. J Clin Endocrinol Metab. 2000; 85:1401-1406. [PubMed: 10770173]

48. Goodwin PJ, Ennis M, Bahl M, et al. High insulin levels in newly diagnosed breast cancer patients reflect underlying insulin resistance and are associated with components of the insulin resistance syndrome. Breast Cancer Res Treat. 2009; 114:517-525. [PubMed: 18437560] 
49. Gunter MJ, Hoover DR, Yu H, et al. Insulin, insulin-like growth factor-I, and risk of breast cancer in postmenopausal women. J Natl Cancer Inst. 2009; 101:48-60. [PubMed: 19116382]

50. Yang G, Lu G, Jin F, et al. Population-based, case-control study of blood C-peptide level and breast cancer risk. Cancer Epidemiol Biomarkers Prev. 2001; 10:1207-1211. [PubMed: 11700270]

51. Maiti B, Kundranda MN, Spiro TP, Daw HA. The association of metabolic syndrome with triplenegative breast cancer. Breast Cancer Res Treat. 2010; 121:479-483. [PubMed: 19851862]

52. Troisi R, Potischman N, Roberts JM, et al. Correlation of serum hormone concentrations in maternal and umbilical cord samples. Cancer Epidemiol Biomarkers Prev. 2003; 12:452-456. [PubMed: 12750241] 


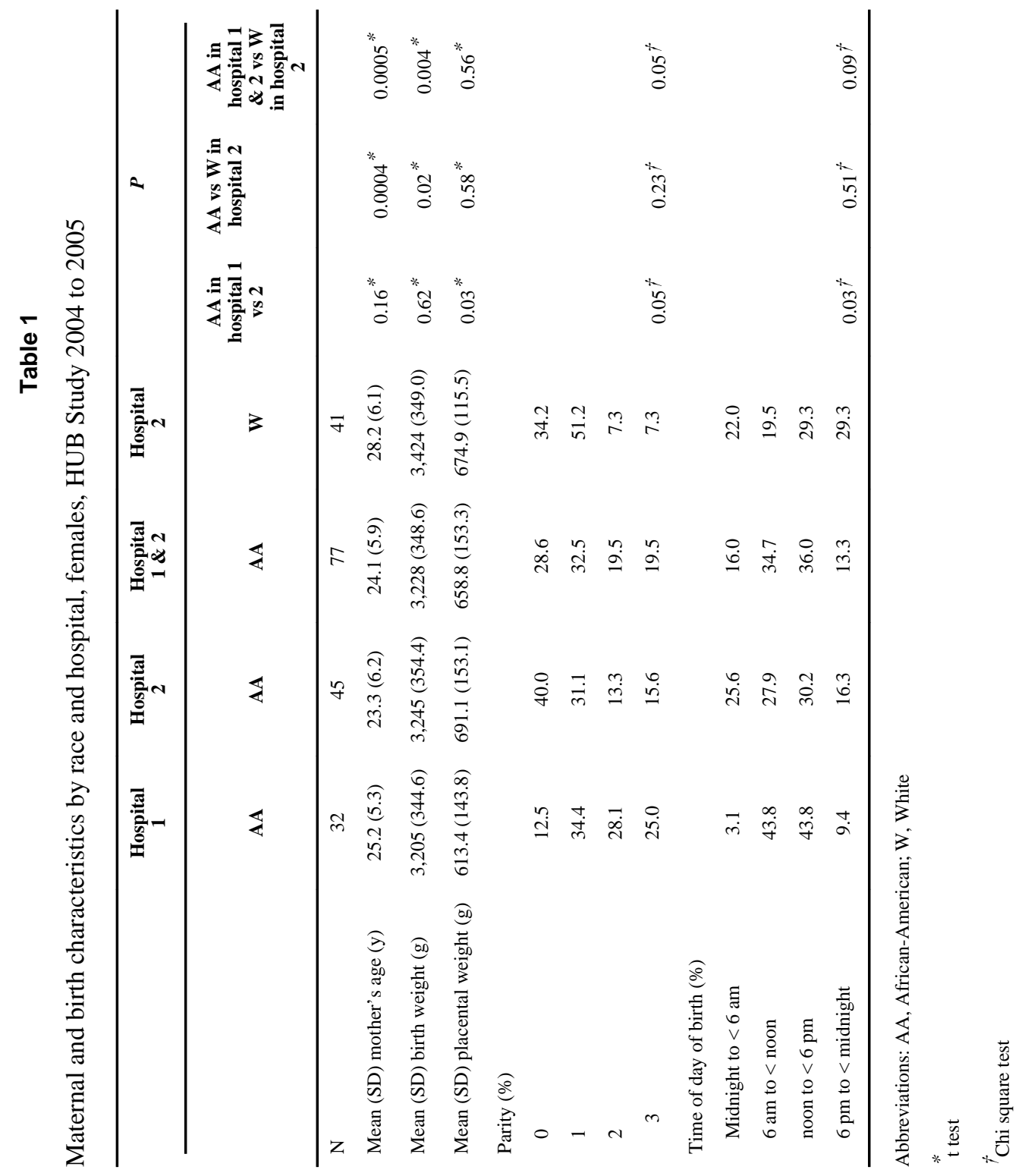


Table 2

Spearman correlation coefficients ${ }^{*}(\mathrm{P}$ value) between maternal and birth characteristics and sex steroid hormone and growth factor concentrations in venous umbilical cord blood, females, HUB Study 2004 to 2005

\begin{tabular}{lcccc}
\hline & Birth weight & Placental weight & Parity & Mother's age \\
\hline Testosterone & $0.12(0.22)$ & $0.08(0.41)$ & $-0.28(0.003)$ & $0.04(0.69)$ \\
DHEAS & $0.002(0.98)$ & $-0.05(0.58)$ & $-0.07(0.45)$ & $0.01(0.90$ \\
Estradiol & $0.05(0.60)$ & $-0.04(0.65)$ & $-0.29(0.002)$ & $-0.12(0.22)$ \\
SHBG & $-0.11(0.27)$ & $-0.07(0.47)$ & $-0.03(0.80)$ & $-0.01(0.96)$ \\
IGF-1 & $0.34(0.0003)$ & $0.14(0.14)$ & $0.09(0.34)$ & $0.13(0.16)$ \\
IGF-2 & $0.07(0.45)$ & $0.08(0.42)$ & $0.09(0.34)$ & $0.08(0.40$ \\
IGFBP-3 & $0.29(0.002)$ & $0.2(0.03)$ & $-0.03(0.79)$ & $0.14(0.14)$ \\
Molar ratios of & & & & \\
Testosterone/SHBG $\left(\times 10^{3}\right)$ & $0.1(0.28)$ & $0.05(0.64)$ & $-0.13(0.19)$ & $-0.009(92)$ \\
Estradiol/SHBG & $0.02(0.84)$ & $-0.03(0.72)$ & $-0.18(0.06)$ & $-0.1(0.28)$ \\
IGF-1/IGFBP-3 & $0.31(0.001)$ & $0.1(0.29)$ & $0.13(0.19)$ & $0.08(0.38)$ \\
IGF-2/IGFBP-3 & $-0.26(0.005)$ & $-0.16(0.1)$ & $0.07(0.47)$ & $-0.11(0.24)$ \\
(IGF-1+IGF-2)/IGFBP-3 & $-0.12(0.21)$ & $-0.11(0.25)$ & $0.14(0.14)$ & $-0.05(0.63)$ \\
\hline
\end{tabular}

Adjustd for race 
Table 3

Distribution of sex steroid hormone and growth factor concentrations in venous umbilical cord blood by race, females, HUB Study 2004 to 2005

\begin{tabular}{lcccc}
\hline & \multicolumn{2}{c}{ AA (n=77) } & \multicolumn{2}{c}{ W (n=41) } \\
& Median & Interquartile range & Median & Interquartile range \\
\hline Testosterone $(\mathrm{ng} / \mathrm{mL})$ & 1.75 & $1.33-2.23$ & 1.65 & $1.45-2.09$ \\
DHEAS $(\mathrm{ng} / \mathrm{mL})$ & 406.8 & $290.3-495.9$ & 382.7 & $289.7-468.3$ \\
Estradiol $(\mathrm{pg} / \mathrm{mL})$ & 5,558 & $3,846-8,837$ & 6,739 & $4,208-10,380$ \\
SHBG $(\mathrm{nmol} / \mathrm{L})$ & 15.3 & $13.0-21.2$ & 17.9 & $12.8-23.2$ \\
IGF-1 $(\mathrm{ng} / \mathrm{mL})$ & 97.9 & $73.3-130.80^{\dagger}$ & 140.3 & $83.8-189.1$ \\
IGF-2 (ng/mL) & 498.6 & $439.7-551.0$ & 554.0 & $495.2-619.1$ \\
IGFBP-3 (ng/mL) & 1,850 & $1,532-2,140 \dagger$ & 2,129 & $1,762-2,326$ \\
Molar ratios of & & & & \\
Testosterone/SHBG $\left(\times 10^{3}\right)$ & 0.37 & $0.24-0.52$ & 0.32 & $0.23-0.48$ \\
Estradiol/SHBG & 1.42 & $0.78-2.48$ & 1.67 & $0.92-2.50$ \\
IGF-1//IGFBP-3 & 0.20 & $0.17-0.25$ & 0.21 & $0.18-0.28$ \\
IGF-2/IGFBP-3 & 0.94 & $0.86-1.14$ & 0.99 & $0.81-1.15$ \\
IGF-1+IGF-2)/IGFBP-3 & 1.18 & $1.04-1.38$ & 1.20 & $1.05-1.42$ \\
\hline
\end{tabular}

${ }^{\dagger} P<0.05$ by Wilcoxon rank sum test 


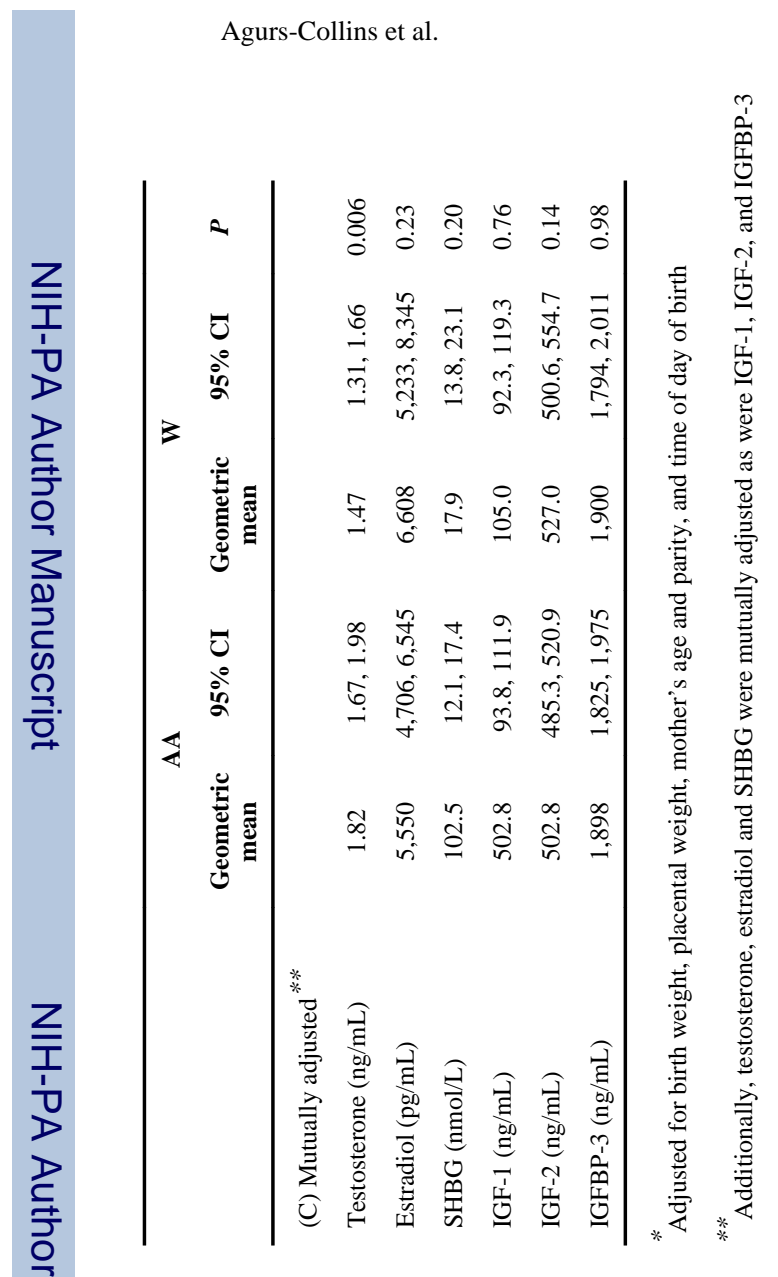

Cancer Causes Control. Author manuscript; available in PMC 2012 June 01. 